\title{
Fruitful artefacts: the role of artistic and creative practices within cultural organisations
}

\author{
Anthony Schrag \\ Media, Communication and Performance Art, \\ Queen Margaret University, \\ Edinburgh, Scotland, EH12, 6UU, UK \\ Email: aschrag@qmu.ac.uk
}

\begin{abstract}
How can artistic processes be positioned inside organisational structures and what are the effects of that repositioning? What is the role of art within cultural management, rather than something that is delivered to audiences? This paper presents a single case study explored via a practice-based methodology looking at what occurs when artistic methodologies are positioned at the heart of cultural management. As cultural organisations are pressured to considered innovative and enterprising ways to survive, the research acts as a reminder that artists are experts in asking 'the rights sorts of questions', and as such speaks to the importance of creativity within the management of culture. This has implications for policy makers and funders, but also cultural organisations that are considering how to re-imagine what it is they do, how and why, and how to make their cultural management more meaningful to themselves, but also their stakeholders.
\end{abstract}

Keywords: participatory arts; cultural management; agonism; artistic research practice.

Reference to this paper should be made as follows: Schrag, A. (2022) 'Fruitful artefacts: the role of artistic and creative practices within cultural organisations', Int. J. Cultural Management, Vol. 1, No. 1, pp.26-39.

Biographical notes: Anthony Schrag is an artist and researcher working both nationally and internationally, including residencies in Iceland, the USA, Canada, Finland, Holland and South Africa. His practice occurs in participatory manner, and central to his work is a broader discussion about the place of art in a social context. He has been the recipient of numerous awards, commissions and exhibitions and his practice-based $\mathrm{PhD}$ explored the relationship between artists, institutions and the public, looking specifically at the productive nature of conflict. The artist Nathalie De Brie once referred to his practice as 'Fearless'. The writer Marjorie Celona once said: "Anthony, you have a lot of ideas. Not all of them are good."

\section{Introduction}

The impetus for the work discussed below emerged out of practice research undertaken over the past 15 years within the UK and internationally. In my artistic and academic work, I am interested in exploring how 'art' ${ }^{1}$ can be positioned inside organisational structures and the effects of that repositioning, asking: What is the role of art within cultural management, rather than something that is delivered to audiences? This paper 
presents a single case study explored via a practice-based methodology looking at what occurs when artistic methodologies, artists and creative practitioners are positioned in heart of cultural management and cultural delivery. The justification of the practice-based methodology is explored below, and the article itself takes a creative approach, presenting the findings in similarly creative and non-traditional format to emphasise their contextual, hermeneutic nature.

As cultural organisations are pressured to considered innovative and enterprising ways to survive, the research acts as a reminder that art and artists are experts in asking 'the rights sorts of questions', and as such speaks to the importance of creativity within the management of culture. This has implications for policy makers and funders, but also cultural organisations that are considering how to re-imagine what it is they do, how and why, and how to make their cultural management more meaningful to themselves, but also their stakeholders.

The paper is framed by Zigmut Bauman and his understanding of the relationship between 'culture' and 'management, and contextualised by examples from the field. It then presents the context for the research and artistic methods and methodology used, followed by a discussion of findings, recommendations and conclusions.

\section{Agricultural beginnings}

Theorist Bauman (2004) frames the relationship between and culture and management as an interlocked and complicated one:

"Just like 'agriculture' is the vision of the field as seen from the perspective of the farmer, 'culture' metaphorically applied to humans was the vision of the social world as viewed through the eyes of the "farmers of the human-growing fields" - the managers

In this text, he describes 'culture' as something that managers and administrators seek to assemble, distribute and organise via imposing norms. Simultaneously, he sees culture as the things that seek to disassemble, diffuse and disorganise management and administrative systems. In other words, he places 'culture' and 'management' in an inexorably intertwined battle where culture is seeking to break through the barriers that managers set, and managers are constantly setting new barriers for culture. "The two sides pursue two opposite purposes and are able to cohabit solely in a conflict-ridden, battle-ready mode." (Bauman, 2004)

This 'battle-ready mode' has played out quite explicitly in my own field of socially engaged art and contemporary examples - Chile (Mandiola, 2018) Finland (Virolainen, 2016) or the current strategies in Scotland (Scottish Government, http://www.gov.scot/ Topics/ArtsCultureSport/arts/culture-strategy) - reflect a zeitgeist of governmental forces and cultural institutions finding new ways to manage participatory artistic process in response to a "necessity of 'civil society' participation in decision-making processes." (Saurugger, 2010) Indeed, in the UK, New Labour's 'social inclusion agenda' is often presented as the quintessential example of participatory cultural management, with the Department of Culture Media and Sport suggesting.

"Culture can also play a key role as a part of the wider "economic drawing power', which is central to the economic transformation of an area." (DCMS, 2004) 
And

"Arts and sport, cultural and recreational activity, can contribute to neighbourhood renewal and make a real difference to health, crime, employment and education in deprived communities." (DCMS, 2004)

Here, the management of culture was largely presented in positive hues, with art being something that was intended to have social benefit. Considering this in relation to Bauman's imagery, the field of cultural management was meant to produce specific outputs: it should be an effective agriculture, and the norms which the management set upon cultural management were about growing social benefit.

From the cultural perspective, however, these processes were seen as an 'instramentalisation' of artistic processes in order to elicit specific political control: Vickery (2007) claimed that government administrations were using culture to "construct civic identities" that were amenable to the state. Miles (2008) argued that such an approach positioned art as "a low cost means to displace factors such as economic decline and social exclusion which result from other areas of government policy." While his critique is broad, what is salient in his critique is his proposition that the mechanisms of management could not ever be able to appropriately deliver 'culture', as such an organic, human, messy process is beyond a manager's structured, managerial purview. Perhaps most applicable to this study, however, is McLean (2012) who asks how "can art institutions perform any sort of critical function when they are so integrated into the workings of the government to the extent they need to provide evidence of their benefit to the economy, urban regeneration and social inclusion?"

Looking away from cultural policy critique and towards institutions, there are also examples of artists ready to battle with managerial systems, with the likes of Andrea Fraser figuratively - and sometimes literally - laying bare the manipulative systems of exploitation that normalise power dynamics within commercial contemporary art management; or the institutional critique of Hans Haake's Shapolsky et al. Manhattan Real Estate Holdings, A Real Time Social System, as of May 1, 1971 which systematically links unsavoury business and personal connections of a museum's trustees to illustrate how the management of art has a moral dimension; Or The Guerrilla Girls who work to expose the gender imbalances within the administrative structures of many of the main cultural organisations. These artists have used their practices to critique the processes management as constraining, limiting and overly-rigid.

And, in response, management can often subsume these critical positions: Fraser is now a highly collectable artist of the system she critiques; Haake's Shapolsky et al. is jewel in Whitney Museum's crown, denuded of any institutional critique it once may have had; and the Tate Gallery now directly and openly support the Guerrilla Girls and their campaigns, despite little change to their gendered collecting habits. As Mouffe (2007) suggests, "there is no transgression that cannot be recuperated by the dominant hegemony." And, so artists emerge again to critique managers, and the managers aim to manage the art, and the cycle goes on: et cetera, et cetera. The examples of the interwoven tension between managers and creatives are plentiful, and thus, Bauman's the fields of 'culture' and 'management' are tied together like warring helices: the snake that eats its own tail. 


\title{
3 Proposal and context
}

Rather than replicate this binary tension, however, I am interested in finding a synthesis between the two, and herein lies the gap within the field. Much of this instinct comes from my $\mathrm{PhD}$ study on 'productive conflict' within art that is positioned in the social realm (Schrag, 2016). The work referred to Chantal Mouffe and her concept of agonism. Agonism is distinct from the oppositional and unproductive antagonist approach - in which different utopian ideas combat against each other - in that it calls for a different formulation of conflict. In an agonistic approach, critical engagement with an opposition is still encouraged, but the social contract is reconfigured towards a mutually beneficial goal. She argues that since we exist as social creatures, conflict cannot ever be eradicated and so agonism ideologically reconfigures conflict into a productive resource. As such, rather than being antagonistic and oppositional to mangers, I was curious if the binary and un-ending struggle could reformulated into something productive. ${ }^{2}$ I therefore contacted the Fruitmarket Gallery in Edinburgh to explore the notion of a productive agonism between the artist and cultural managers.

This organisation was chosen as it was small and well-respected cultural organisation within my hometown: it was therefore easy to access, and as a small organisation with less than 20 office staff, too, it presented a fairly self-contained organisation within which my research could function effectively. Due to its respect within the wider Scottish cultural field, too, it also presented an example of a well-managed institution, and therefore could be considered exemplary of a productive relationship between 'artist' and 'managers'.

As an organisation, The Fruitmarket Gallery (https://www.fruitmarket.co.uk/about-2.) declares that it:

\begin{abstract}
"programmes exhibitions with the best Scottish and International artists and enriches these with a wide variety of cultural and educational events. We are committed to making contemporary art accessible without under-estimating audiences or compromising art or the ideas it enacts. We create a welcoming space for people to think with art in ways that are meaningful to them - for free."
\end{abstract}

It therefore also aligned with my own socially engaged understanding of accessible artistic spaces. Subconsciously, too, perhaps its history as a former fruit and vegetable market reference Bauman's imagery of agriculture.

I therefore contacted them in April 2018, suggesting a week long residency within the offices of the gallery. Framed within a practice-based ontology, I proposed a research question to guide the work: What is the role of an artist within a cultural organisation in regards to its management? This question was not framed to unduly challenge the organisation, but rather as a starting point for shared inquiry. The objective of the study was an exploratory process to discover what the role of an artist within an arts organisation could be. It proposed to be exploratory process (Bryman, 2012) which would an iterative process, reflecting on data as it is gathered in order to further establish insight into the phenomena. Thus, the work took place during a week in August, 2019 when the Fruitmarket agreed I could be in residence with them to explore these ideas. 


\section{Methodology and methods}

The following section presents the methodological justifications, goes on to defines artistic research and participatory-arts methodologies, and then discuss the method of interpretive policy analysis (IPA).

The research was practice-based, by which I mean that my artistic practice guided my inquiry. Traditional research from a positivistic world view is systematic and repeatable; artistic research however is disruptive and unique. While the ontology of these research strategies might be different, they both produce knowledge, albeit knowledge of different kinds. As such, they should not be set at odds, but rather be understood as different strands of the same Gordian Knot. The specific work of this paper is based within participatory-arts methodology that is set within a socially constructivist ontology and a hermeneutic epistemology that examines the contextual, interpretive nature of meaningful human actions and the products of such actions. The work of this study therefore relies of the researcher - me, myself and I - to grasp the subjective meaning of the actions I witnessed (and to which I contributed) (Bryman, 2012) in order to develop knowledge. I cannot therefore be made distinct from this knowledge, and thus use the untraditional ' $\mathrm{I}$ ' throughout this paper.

While this approach may stand in contrast to the traditional systematic and repeatable processes of research within a positivist ontology, it cannot be denied that such an approach still produces knowledge. As Sullivan (2013) suggests "Artists emphasise the role of the imaginative intellect in creating, criticising, and constructing knowledge that is not only new but also has the capacity to transform human understanding." The work developed therefore aims to find new ways to transform human understanding about this subject. The methodological framing could therefore not be presented in a way that aligns to positivist, systematic and more traditional approaches as these would neither suit the knowledge sought nor the nature of artistic and participatory research.

While participation is a complicated term - perhaps as complicated as the definition of 'art!' - but I place my understanding in regards to the notion of democratic theory (Carpentier, 2011) that conceptualises agents (people) as active citizens who engage in (political) decision making processes with each other, and the aim of egalitarian participation is to ensure an equity of encounter (Rancière, 2006). Within an artistic context, Participatory-arts processes consist of engagement of and co-authorship with other groups and/or individuals. The practice can "include any art-form which involves people and communities in debate, collaboration or social interaction. The participatory element is key, with the artworks created often holding equal or less importance to the collaborative act of creating them," (Tate, http://www.tate.org.uk/art/art-terms/s/sociallyengaged-practice). It focuses on the processes and dialogical nature of engagement, and aesthetics lie within "a collective meaning-making, rather than a focus on producing traditional artefacts" (Schrag, 2018). In other words, it does not result in objects but rather the artworks of participation are processes and dialogues. As such, I applied a method of IPA to be able to frame these processes and dialogues in a manner that was useful for the staff, as it related to their work experience.

IPA is field of study pioneered by scholar Dvora Yannow. It is "informed by postpositivist social theory which attends to matters of representation through language, text and symbol in the constitution of social life" (Yanow, 1996). It is a mechanism to 'read' policy in a way that pays close attention to the meanings and effects/affects of that policy. At the Fruitmarket, I was most interested in 'policy artefacts' elements of IPA: 
"[Policy] artefacts are shown to symbolise tacitly known meanings as well as those which are part of a policy's explicit language. Not only do implementers and other situational actors interpret these artefacts; the policy and these interpretations maybe 'read' as a 'text' about societal values and identity." (Yanow, 1996)

and

"Dress codes, agency names, program and space design, and so forth are artefacts of an organisation. The artefacts embody the values and beliefs of the organisation, and they are meaningful for organisational members in ways that are particular to their context. Artefacts, together with their underlying beliefs and values, constitute the culture of the organisation." (Yanow, 1996) (emphasis added)

Thus in using IPA, I presented to the staff artefacts to be read, discussed and analysed in a way that could reveal the 'true' meanings and intentions of an organisation and compared/contrasted with the stated or explicit meanings. The approach operates similarly to Latour's Actor Network Theory in that the systems being examined "could be analysed and interpreted through the interactions of actors and networks," (Crawford, 2005) and IPA similarly aims to mine the implicit societal values embedded into an organisation's physical/social structures to reveal power-structures. It is important to note that using IPA does not suggest that the implicit and the explicit culture of an organisation are necessarily mismatched, but rather these tools can be utilised to explore the tacit or subconscious 'truth' of an organisation, and these are worthy of interrogation.

As such, reading these artefacts at the Fruitmarket Gallery became a process by which I could read, but also interpret with the staff. Below, I describe my reading/interpretations of 4 of these, followed by a 5th 'intervening' artefact. After this, I include feedback from staff about my interpretations and policy artefact interventions, providing some final data about what happens when artistic methodologies are positioned in heart of cultural management and cultural delivery.

\section{Policy artefacts - five insights into the management of The Fruitmarket Gallery}

The choice of attention given to following artefacts is entirely subjective and has been made on the basis of a short, 5-day micro-residency, and so I do not claim to have a full understanding of the entire operational mechanisms and inter-relationships. However, in this short time I found five policy artefacts for discussion and assigned them the following 'theme titles':

1 value of knowledge

2 social justice

3 communitarianism

4 'positionality'

5 defence/offence (weapons). 


\subsection{Policy artefact 1 - value of knowledge}

When discussing the logistics of my 'micro-residency' at the Fruitmarket, one of the main concerns was space. The offices, I was told, were quite small and cramped, with little room for extraneous activities. It was suggested the residency occur in August, during the Edinburgh Festival, as "There should be a little more space in the office during these weeks as people will be engaging with festival activities...so there will be desks available." ${ }^{3}$ The impression given therefore was of a cramped office with little room to manoeuvre. Indeed, on starting the project I found the office space was limited and small.

Interestingly, however, on entering the office, the first thing I noticed was a large bookshelf that contained previous publications for exhibitions, artists monographs, exhibition catalogues and other contemporary art publications. There are also extensive administrative and documentary archives - both for management as well as curatorial purposes. On my first day, I calculated the volume of these books and archives as being about 9.9 cubic metres: This is approximately equivalent to the size of an adult African elephant, metaphorically wandering about the offices.

The policy artefact of these books and archives can be analysed in two ways: firstly, in having a large repository of books and archives physically and visually be the first thing one experiences could suggest that these artefacts hold important performative value for the organisation. It is interesting to note that this 'first impression' is also replicated in the main gallery space (as well as the director's office) where, literally, the first thing one encounters are books. That this is apparent in both the managerial as well as public experience suggests that the value is held throughout the building and there is little mismatch between the internal value systems and what is presented for a public consumption. Books and Archival history - both signifiers of and repositories of knowledge - are therefore presented as holding a primary place within the institutional psyche. They (and what they represent) are held in high esteem, over and above any other possibility. Consider the difference sense of welcome that would emerge if the first encounter a visitor had is of a box office (commerce), a receptionist (bureaucracy), a security guard (power), or a series of couches (comfort).

The second reading more specifically relates to issues of management, and links back to the initial concern: that of space. The elephant in the room (metaphorically, and by volume) is that these books and archives are more important than other management strategies. Simply put: rather than provide bigger desks, more personal space, or a more comfortable and accessible offices, the Fruitmarket would rather keep these artefacts accessible and visible. They could choose to sell the books or store them elsewhere (for example, there is a large unused space above the door), or keep the archives off-site or make them digital. However, the unspoken choices and tacit agreement is that these books and archive - this value of knowledge, history, information and insight - should be on-site, accessible and central to the management, operation and identity of the Fruitmarket.

\subsection{Policy artefacts 2 - social justice}

On arrival, I noticed a brass bell, mounted on the wall which the staff referred to the 'feminist bell'. I interpreted this as something to be rung if someone said anything misogynistic. It was explained later that one of the only men in the office was irked at the endless negative comments directed towards men by the predominately female staff and 
was actually to be rung to call out gender hypocrisy. I suggested re-naming it the 'intersectionality bell' that could be rung if anyone said anything that prejudicial relating to age, race, class, ability, etc., to which people responded positively. It made me curious to explore to what extent Social Justice ${ }^{4}$ played within the organisation. While I saw and heard many examples of the staff's personal commitment to social justice, it was the toilets where this policy artefact manifested organisationally.

The Fruitmarket is located directly next to Waverley Station, Edinburgh's main rail station and as such places often do, the area holds many homeless people. The station operates paid-access only toilets, and so these homeless have little access to toilet facilities. At the same time, Edinburgh City Council, in a bid to save money, as been closing down and selling off public toilets. Instead, they have been offering private organisations $£ 500$ annually to become a public toilet facility, to be advertised on-line (Edinburgh City Council, http:/www.edinburgh.gov.uk/info/20003/business/1306/ community toilet_scheme). In one of their staff meetings the Fruitmarket revealed that they while had already been operating as a public toilet for the homeless for many years, it had been decided the organisation was also going to become an official 'public facility' for Edinburgh Council.

In a time when finances for arts organisations are minimal, this would be an easy way for Fruitmarket to add to their coffers. However, rather than take that money into their own purse, the organisation has committed the $£ 500$ to providing free feminine hygiene products in the toilets as part of a campaign to end Period Poverty. ${ }^{5}$ Cynically, this gesture could be read as a marketing campaign to attract socially conscious millennials however, there has been no marketing or news about this. It has not been launched or advertised: it is merely something that is an accessible service for those requiring free public facilities can utilise. It has been undertaken quietly because it 'is the right thing to do' (Director, Fruitmarket Gallery at the Weekly Staff Meeting, Thurs 23rd Aug, 2019). This act suggests an embedded, honest and unsensational commitment to Social Justice throughout the organisation.

\subsection{Policy artefacts 3 - communitarianism}

The small kitchen in the office contains several images of the staff team at weddings or other social occasions: they are images of a cohesive, friendly group that obviously enjoys each other's company and suggests a policy artefact of communitarianism.

Similarly, the entries to the offices are locked and only accessible via a passcode activated door. While these make sense as the office contains not only expensive computer equipment, but also sensitive financial and/or personal documents, it seems that everyone in the organisation has that access code. Through-out my time, every level of staff came in and out of the offices. This suggested there was a level of trust and communal sharing throughout the organisation which meant that everyone was equally allowed into that organisational space: that, literally, everyone was equally part of the team, regardless of their position. (Relatedly while the director did have her own office, its door was only ever closed during sensitive meetings, but otherwise always open.)

This artefact of equity seemed most apparent, however, during a delivery of some flat-packed tables that needed to be moved to an adjacent building. Without fuss, hassle or goading, the entire staff stood up to help and, for a moment, the director was lugging heavy boxes with the marketing officer; the deputy director was helping the finance 
officer; and the administrative assistant and I carried table legs. Everyone figuratively and literally - got their hands dirty; everyone chipped in. It appeared hierarchy did not exist.

This lack of hierarchical division was further illustrated in a staff meeting where a member of staff gently and good-naturedly mocked the director, and she good-naturedly responded with her own quip. This small exchange of interpersonal friendliness suggested that while a hierarchy did managerially exist, it was structural rather than interpersonal. There was an understanding of - and commitment to - communitarianism that seems to suggest we're all in this together.

It is difficult to know if this specific artefact is a result of management or the specific constellation of the individuals working in the gallery. Or even if this is consciously cultivated by the managers: regardless however, this level of equity seems to produce a highly productive and dedicated staff.

\subsection{Policy artefact 4 - desk positionality}

The least analytically resolved artefact relates to the physical position of staff within the management offices. Within the main office, there are 15 staff, including administration, finance, program manager, deputy director, fundraising, outreach and schools managers, to name a few. The interesting artefact is that all the desks apart from four of these individuals face away from other staff members, and instead face towards a wall.

I refer to this as the least resolved as I am unsure how to interpret it appropriately. I have speculated that it might work in collaboration with the above artefact in that a collegiate workspace which constantly values 'everyone together' might require a counter-balancing force wherein the individual might could reassert their independence and/or distance themselves from the group for either personal or professional reasons. However, I simply did not have time in the five days I was present to unravel this further and more research is needed.

\subsection{Policy artefact 5 - defenceloffence (weapons)}

IPA suggests that tacit meanings can also - carefully - consciously be inserted into organisational space in order to align values more closely. The above artefacts were revealed through a process of creative engagement within the organisation, and this last artefact refers to work where I actively and artistically intervened on management, and where the artistic process was more visibly inserted into the management scheme.

The Fruitmarket is in the process of expanding, with funding and planning being secured that would see the gallery take ownership of a neighbouring building. The new space would provide an enlarged gallery but also an outreach and education studio as well as other benefits such as expanded office space. In discussion with some of the staff, however, they were adamant that they did not want to use the terms such as 'expansion' or indeed refer to any terms that could relate to notions of colonisation. They did not want to be seen as aggressors occupying new space, but rather an organisation who needed to expand in order to do what they do better. This artefact relates both their social justice commitment and its ethical alignment with post-colonial and anti-racist thinkings.

However, the fact remained that if the funding was secured, the organisation was going to expand, and left me with a question: Can one be a communitarian, social-justice-minded group but also be an expanding, growing force? I was reminded of 
Edward Said who wrote: "Every empire... tells itself and the world that it is unlike all other empires that its mission is not to plunder and control but to educate and liberate" (Said, 2003). I presented this quote to the Fruitmarket, being intentionally inflammatory. As discuss above, in my work, as I am interested in conflict and agonism and I often use these concepts intentionally to find 'push-back'; to find the borders of things. In Lewis Hyde's (1998) text Trickster Makes This World: How Disruptive Imagination Creates Culture, he develops a thesis which arises from an ethno-anthropological examination into the character of the 'the trickster' in various cultures throughout human history. In it, he suggests the trickster

"is a boundary crosser. Every group has its edge, its sense of in and out, and the trickster is always there, at the gates of the city... He also attends the internal boundaries by which groups articulate their social life. We constantly distinguish - right from wrong, sacred from profane, clean from dirty, male from female, young and old, living and dead - and in every case Trickster will cross the line and confuse the distance... [this definition] needs to be modified in one important way, for the there are also cases in which Trickster creates boundaries; or brings to the surface a distinction previously hidden from sight."

Hyde presents this trickster as an essential part of the human psyche whose purpose is not to fix, but to provide a 'disruptive imagination' that challenges the smooth functioning of hegemonies. In this way, the trickster enacts 'productive' conflict to social norms in order to examine and critique those norms. As such, the image of the trickster aligns with Mouffe's concept of Agonism and within the trickster stories, it is the resistance to his/her acts that indicate when social, structural and hegemonic norms are being challenged, and thus are signposts to when 'art' - as a thing that problematises the world - is called into being.

I was therefore interested at the resistance the Fruitmarket showed to the idea of expansion and I decided to push deeper into this conflict and develop a series of individual 'weapons' for staff that they might use as part of this 'expansion'. To be made only from materials found in the management office, I was interested how the weapons could interrogate the policy artefact of resistance to 'expansion'. Working with alongside staff, we developed weapons would be metaphorical manifestations of tools that they might need as they expand organisationally. While many staff thought them humorous, they were all trepidatious with them. Indeed, the director refused to touch any of them when presented. Most seemed to edge away from them as if they might physically attack them, rather than being inert objects, as one of the feedback responses clarified:

\begin{abstract}
"Many of us reacted strongly against the idea (that Anthony proposed) that our redevelopment should be framed in colonial terms as a kind of aggressive expansion. The making of 'weapons' to articulate this sat awkwardly with many of us since it did not represent the Fruitmarket ethos." (Anonymous staff response, 2018)
\end{abstract}

The artefact of their resistance to both the notion of expansion and to engaging with the weapons suggests a lack of confidence in being able to claim and occupy space. To problematise this I suggested that no one would deny the expansion of a hospital. In other words, the concept of 'expansion' is not necessarily colonial, and found it curious that this organisation has a resistance to the concept and the metaphors of expansion: This could represent either a mismatch between some of their policy artefacts, or a lack of clarity as to what this growth/expansion might mean for the staff. This needs to be explored further in depth. Either way, the artefact of the staff's response suggests unease 
in relation to the subject of growth and expansion. However, another feedback response suggested there was a productive response to my weapon intervention:

"[The Weapons] did cause discussion, and made us think about the way we present ourselves to the outside world. This helped us articulate the kind of language and metaphors that we would prefer to use, and think about the way these affect our public image."(Anonymous staff response, 2018)

Figure 1 Digital documentation of 'weapons' objects developed with Fruitmarket Gallery staff
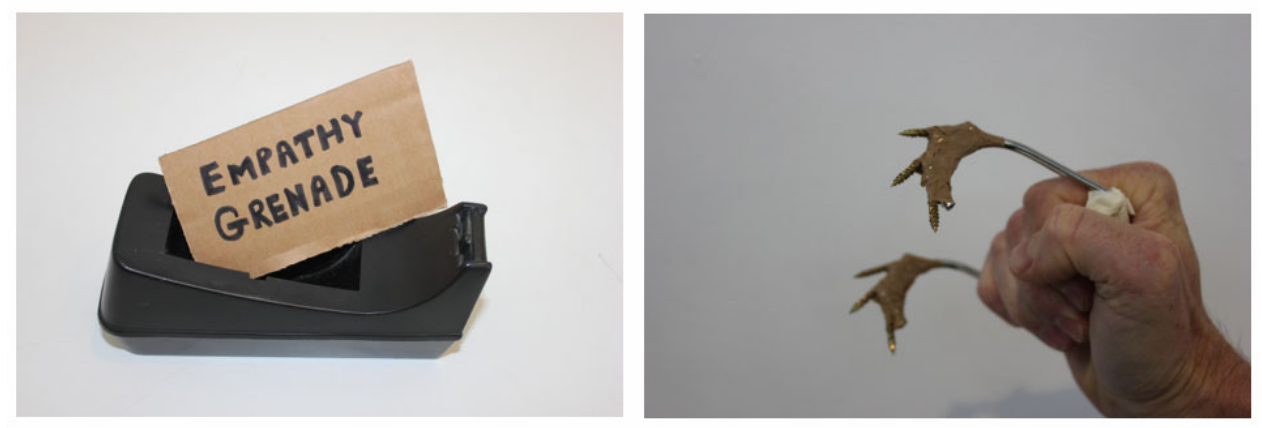

Source: Schrag (2018)

\section{Feedback and conclusions}

As I have written above, the reading of these Policy Artefacts has been entirely subjective and has been made on the basis of a short, 5 day micro-residency, and so I do not claim to have a full understanding of the entire operational mechanisms and inter-relationships. However, in this short time I was able to decipher and reveal commitments to social justice; discover an approach to communitarianism that manifests in a productive, collegiate and effective workforce, and the organisations' commitment to (and value of) knowledge. I was also able to intervene on management processes via creative practice-based research on the Fruitmarket's expansion and how it is envisaged by the staff as a collective whole.

The original question set out in this research was to explore what occurs when artistic methodologies, artists and creative practitioners are positioned in heart of cultural management and cultural delivery. An anonymous staff survey completed after my residency with the Fruitmarket was completed and I have selected four responses that link to this question:

"I felt somewhat under scrutiny, though not in a negative way - I was just more aware of the way that I divided up my time, how I worked and how I interacted with my colleagues. It gave me a level of self-consciousness I don't normally have." (Anonymous staff response, 2018)

"I valued having the presence of a 'critical friend' - a fresh perspective on conversations and operations. Anthony's presence will affect how we think about our equalities actions, for example. Having someone 'other' to the organisation helps to reflect on things we take for granted that we just do, and that was refreshing" (Anonymous staff response, 2018) 
"Your presence injected a bit of space to think differently about what we do, and injected much needed fun and collaboration into the process. It created a welcome space to talk about the more touchy/difficult questions." (Anonymous staff response, 2018)

"We have never had an artist work with us as a 'critical friend' before, and I think it was instructive and productive...It felt right to have an artist in the midst of things, as putting art and artists at the centre of what we do is what we strive for." (Anonymous staff response, 2018)

Artistic research does not aim to provide facts in the same way as the hard or social sciences. As above, artistic research emphasises "the role of the imaginative intellect in creating, criticising, and constructing knowledge that is not only new but also has the capacity to transform human understanding." (Sullivan, 2013) As such, this research hoped to create, criticise and construct knowledge about the role of an artist within a cultural organisation.

These quotes, therefore, do provide useful documentary evidence into the effects of an artist working within an organisation. It appears that the artist can act as a 'critical friend' and 'help reflect' on difficult questions that they might be facing, be they ideologically or managerially; they offer a space to 'think differently' and provide a 'welcome space' that can be 'fun and collaborative'.

Most importantly to me is the concept that the staff felt it was 'right' to have "an artist in the midst of things, as putting art and artists at the centre of what we do is what we strive for." Here, the concept that art is not just the service or product, but is integral to its organisational survival aligns with my adaptation of Bauman's notion that the 'culture' and 'management' do not have to be at odds, but could operate productively.

Obviously there are limitations to this study, the main being that of contextualisation: not every artist is the same or has a similar practice and so not every artist can work effectively within organisations. However, the fact remains that in this one case study, a single participatory artist working within an organisation has been able to productively intervene on management processes, and provide some data on how this was a broadly positive experience.

There is also a limitation of hosting: In previous institutions in which I have worked, I have often operated in dysfunctional managerial spaces, and it is this disfunction that often provides me with the most grist for my practice. When working with the Fruitmarket, however, I was often frustrated at the level of co-operation, communication and effective functionality the organisation displayed. Organisationally, the Fruitmarket was not only was secure enough to let a stranger into their inner sanctum, and reflective enough to participate in works that aimed to challenge their organisation, but also kind enough to treat me as an equal.

Their commitment to artistic processes within managing a cultural organisation suggests a contrast to Bauman's 'battle ready' Managers and Cultural agents locked in a warring helix. Instead, they suggest a more sustainable perspective more akin to the notion of permaculture. Developed in the 1970s out of the nascent environmental movement, it is an elision of the words 'permanent' and 'agriculture', the practice looked to the sustainable farmers of the Mediterranean and beyond who had been growing orchards and vineyards for millennia for insight. This practice understood that the modern, mechanistic understanding of the land as something to be dominated was unhelpful and instead the relationship between the field and the farmer could be reframed into a dialogue, rather than a war. Similarly, the Fruitmarket understands that the 
Manager and the Cultural agent are not locked in a helix of battle, but are rather two parts of the same fruitful whole.

As such, cultural organisations that are considering how to reimagine what it is they do, how and why, and how to make their cultural management more meaningful to themselves, but also their stakeholders might consider inviting artists to work within their inner sanctums of management.

This is not a new or novel approach: the Artist Placement Group operating in the 1960s organised placements and residencies in governmental departments and businesses, under assumption that "art had a useful contribution to make to the world" (Bishop, 2012). What is different about my proposal is that artists work within management of cultural organisations. It seems profoundly curious that cultural organisations who have supported artists working in different structures - in business, in education, in policy, in health - seem resistant about artists working within their own management. Policy makers and funders should therefore consider how to support artists working productively within cultural management to the benefit of the cultural sector as a whole.

\section{References}

Bauman, Z. (2004) 'Culture and Management', Parallax, Vol. 10, No. 2, pp.63-72.

Bishop, C. (2012) Artificial Hells: Participatory Art and the Politics of Spectatorship, p.177, London, Verso.

Bryman, S. (2012) Social Research Methods, Oxford University Press, Oxford.

Carpentier, N. (2011) 'The concept of participation. If they have access and interact, do they really participate?', Communication Management Quarterly, Vol. 21, No. 2, pp.164-177.

Crawford, C. (2005) 'Actor network theory', in Ritzer, G. (Ed.): Encyclopedia of Social Theory, pp.1-4, Thousand Oaks, CA, SAGE Publications, Inc.

DCMS (2004) Creative Industries Mapping Document, Department of Culture, Media and Sport/Stationery Office, London, p.38.

Edinburgh City Council (n.d.) Sign Up to the Community Toilet Scheme, The City of Edinburgh Council [online] http://www.edinburgh.gov.uk/info/20003/business/1306/community_toilet _scheme (accessed 22 October 22 2018).

Fruitmarket Gallery (n.d.) About' Fruitmarket Gallery [online] https://www.fruitmarket.co.uk/ about-2/ (accessed 18 October 2018).

Haake, H. (1971) Shapolsky et al. Manhattan Real Estate Holdings, a Real-Time Social System, 1 May, [Gelatin silver print and printed and typed ink on paper], Museum of Contemporary Art Barcelona (MACBA), Barcelona.

Hyde, L. (1998) Trickster Makes This World: How Disruptive Imagination Creates Culture, Canongate, Edinburgh and London.

McLean, J. (2012) The Open Council: A Practice Led Enquiry Into Improvisation and the Self-Institution, $\mathrm{PhD}$ thesis, Newcastle-upon-Tyne, Newcastle University.

Mandiola, S.P. (2018) 'Paradigms of participation in the National Council for Culture and Arts: challenges on representation, recognition, access to creation and reception in post-dictatorship Chilean public cultural policy', International Journal of Cultural Policy, Vol. 24, No. 2, pp.164-185.

Miles, M. (2008) 'Critical spaces' in Cartiere, C. and Willis, S. (Eds.): The Practice of Public Art, Oxford, Routledge.

Mouffe, C. (2007) Agonistic Politics and Artistic Practices, (Lecture) Glasgow School of Art, Glasgow, 2 March. 
Rancière, J. (2006) 'The ethical turn of aesthetics and politics', Critical Horizons 7:1 in Malaise dans l'Esthetique, Paris, Galilee, pp.143-173.

Said, E. (2003) Empire, Los Angeles Times, 20 July.

Saurugger, S. (2010) 'The social construction of the participatory turn: the emergence of a norm in the European Union', European Journal of Political Research, Vol. 49, No. 4, pp.471-495.

Schrag, A. (2016) Agonistic Tendencies: The Role of Conflict within Institutionally Supported Participatory Practices, $\mathrm{PhD}$ thesis, Newcastle University, Newcastle.

Schrag, A. (2018) 'Non-visual aesthetics: seeing the world with our bodies', Visual Culture in Britain, Vol. 19, No. 2, pp.216-236.

Scottish Government (n.d.) Developing a Culture Strategy for Scotland, Scottish Government [online] http://www.gov.scot/Topics/ArtsCultureSport/arts/culture-strategy (accessed 23 October 2018).

Sullivan, G. (2013) Art Practice as Research: Inquiry in the Visual Arts, SAGE Publications, London.

Tate (n.d.) Socially Engaged Practice [online] http://www.tate.org.uk/art/art-terms/s/sociallyengaged-practice (accessed 18 October 2018).

Vickery, J. (2007) The Emergence of Culture-led Regeneration: A policy concept and its discontents, Centre for Cultural Policy Studies, Coventry, University of Warwick.

Virolainen, J. (2016) 'Participatory turn in cultural policy? - An analysis of the concept of cultural participation in Finnish cultural policy', Idunn: Nordisk Kulturpolitisk Tidsskrift, Vol. 19, No. 1, pp.59-77.

Yanow, D. (1996) How Does a Policy Mean? Interpreting Policy and Organisational Actions, Georgetown University Press, Washington, DC.

\section{Notes}

1 While an ambiguous term, here I mean it to refer to both artistic processes and thinking, but also the objects of 'art' themselves. Nor does not assume that 'the artist' is the only one who can produce these processes or objects, rather that 'art' can be those things that aim to problematise the world through inviting reflection, productive critique or disruption.

2 By 'productive', I do not refer to any capitalist notion of 'production' but instead use the word in relation to its 'generative' possibilities.

3 Employee 'RB' in email to author, 20 June 2019.

4 A highly contested term, and I recognise that the definitions of which specific 'social' and whose specific 'justice' needs to be delineated. However: in this context, I refer to the generalised of the term which pertains to a fair and just relationship between the individual and society.

5 This campaign raises awareness that poverty impacts girls and women's access to feminine hygiene products, and thus can impact factors such as if a young woman will attend school or be able to work. 